\title{
Banking front-line personnel assessment by fuzzy logic approaches
}

\author{
Vladimir Koretskiy ${ }^{1, *}$, Marina Degtiareva-Galiakhmetova ${ }^{1}$, and Evgeniy Kostitsyn ${ }^{2}$ \\ ${ }^{1}$ Kalashnikov Izhevsk State Technical University, Institute of Digital Economy, 7, bld. 1, Studentcheskaya str., Izhevsk, 426069 , \\ Russia \\ ${ }^{2}$ PJS Company BystroBank, 18, Krasnogeroiska str., Izhevsk, 426008, Russia
}

\begin{abstract}
The article is dedicated to the qualitative assessment of banking personnel and the interpretation of the results with a developed fuzzy logic expert system. The authors proposed to evaluate human resources based on the Company Loyalty, Customer Service Quality and IntraCorporate Communication which are linguistic terms for personnel to be assessed. To interpret the results of the received staff assessment, a fuzzy expert system was developed which enables the Business Efficiency of Personnel to be estimated. The expert system was tested at the front-line office of the regional bank. Regression and correlation analysis revealed high correlations between the Business Efficiency of Personnel and the quantitative results of employees. The practical relevance of the research is conditioned by the growing need to assess credit managers during the trial period or at the introduction of new products, while quantitative indicators are absent. The methods used for research comprise survey, ranking of the factors and factor analysis.
\end{abstract}

\section{Introduction}

The effectiveness of personnel management becomes an essential factor in ensuring the competitiveness of any economic entity, including in the banking sector. For a few medium-sized, regional banks in Russia, this factor is becoming a key factor of surviving in their competition with transnational bank chains. At the same time, it should be noted that the quantitative criteria of staff assessment do not always sufficiently represent the value of the employee to the company. In particular, they failed to reflect the risks associated with, for example, lending, since they generally account for only the number of contracts gained by a bank clerk and their cost.

Staff assessment, as a decision-making process, involves determining the level of compliance of individual indicators of an employee with the requirements imposed on him by the employer. Besides, the staff assessment, especially for front line staff and managers, should identify both qualitative and individual characteristics of them, and the amenability to the team playing, flexibility to new demands and conditions, personalities and customers' challenges. Labour activity of the credit manager takes place in a volatile environment.

As noted in the references relevant to the subject, in the vast majority of banks there is no formalized mechanism for staff assessment and that is one of the main reasons for the lack of efficiency of performance of staff members [1]. As a rule, this has the following negative results:

- increased turnover of staff;
- vast of vacant jobs in the bank's subdivisions, unfilled for a long period;

- labour dispute;

- complaints from consumers;

- losses of efficiency of the bank's employees;

- loss of competitiveness.

Most banking organizations face challenges in institute procedures for staff to be assessed including the following ones: low level of the amenability to work ethic, subjectivism or excessive formalism in the interpretation of results, lack of follow-up measures, in particular, the motivation means based on data fetched while the evaluation of personnel was carrying out.

All staff assessment criteria, regardless of economic sectors and areas of activity of the entity, can be divided into three broad groups. They are:

- results of individual actions;

- behavioural characteristics;

- merits of the employee.

Whereas the first group usually includes quantitative indicators of the staff performance for a period, the second and third are subjective, evaluative or qualitative. At the same time, their relevance to the staff assessment is not lower than quantitative indicators weight, as they determine the staff morale, customer satisfaction, delayed risks, readiness team player to alter or take up a new project. In particular, as pointed out by some authors [1, 2] the following factors influence final results:

- biological (sex, age, mental and physical abilities);

- social and economic (state of the economy, standard of living, social protection);

- technical and organizational (challenges, conditions and complexity of work);

*Corresponding author: vpk1973@yandex.ru 
- social and psychological (attitude to work, the psychological climate in the team);

- market (competition, inflation).

These all factors should be allowed for a comprehensive assessment of staff performance to be carried out and it increases the credibility objectivity and reliability of the findings of an evaluation of personnel activity point out these authors.

On assessing personnel to interpret qualitative indicators the approaches of fuzzy logic proved their effectiveness. Currently, fuzzy logic is used in the automotive, aerospace and transport industry, robotics, risk evaluation, management, including personnel assessment in the financial sector [3]. The way of fuzzy logic implementation for personnel management is shown in numerous works $[4,5,6]$.

The fuzzy analytical approach for study competencies in employee selection was developed by Akyol \&Guler [7]. They suggested a fuzzy expert system to select project managers by comparing the competencies of applicants.

There are some works on measurement analytical competencies of employees by fuzzy logic being applied [7]. For example, Kalvakolanu \& Madhavaiah focused on the capability of the staff to demonstrate the analytical competencies.

Competency assessment methods proposed by Holt et al. for personnel to be assessed [8]. Jevscek stated that the assessment competencies of professionals fit the fuzzy logic approach [9]. Analytical abilities and the performance of HR professionals and appraisal using fuzzy evaluation methodology are relevant to this research $[10,11]$.

Thus, it can be concluded that both quantitative and qualitative indicators should be taken into account in assessing staff. At present, it is necessary to solve the problem of a comprehensive assessment of the personnel, i.e., their professional, personal and business qualities, which are necessary to be assessed as the effectiveness of the employees. At the same time, it should be borne in mind that efficiency means performance, i.e., the ratio of achieved result to planned ones - state some researchers [1].

\section{Methodology}

Among the factors relevant to personnel assessment the essential are the following ones:

- corporate culture (strategic goals, values, regional cultural features, management style, system and communication features);

- regulatory framework (legislative acts corporate standards and rules);

- number and quality of staff;

- staff turnover rate;

- seasonality of business (allowing for peak load or downtime) [2].

For example, the indicators related to the first factor, corporate culture, are qualitative. As a result, due to erroneous management decisions amenable to personal sympathies and dislikes of HR managers, serious risks for the management of human resources are rising. It should be noted that risks in the credit sector can be assessed on fuzzy logic bases [12].

The problem is aggravated by the fact that the results of actions of an individual employee performed under circumstances of odds financial risks and uncertainty are extremely unpredictable and hardly could be estimated both qualitatively or quantitatively. This issue is particularly common in the group assessment of staff or in cases where the contribution of a particular employee cannot be distinguished from the teamwork results (Business Game Laboratory).

It should be added that the assessment of the personnel is a quite challenging process both for the personal probation and adaptation because of lack of quantitative data.

For quantitative and qualitative parameters of evaluation indicators to be determined appropriately, it is extremely recommended:

- to avoid amenability to any single indicator or group of ones for fear that other equally important aspects of employee activity could be left beyond observation;

- to determine a sufficient number of indicators to maximize the performance of the staff and not to be overloaded with data.

As factors of assessment of loan officers, based observations, surveys of experts in the banking sector and factor analysis were chosen the following:

- Behaviour Towards Colleagues and Costumers.

- Customer Service Quality.

- Company Loyalty.

As an output variable defined the following one:

- Efficiency of the Manager.

It should be noted that indirect or qualitative assessments characterize the performance of an employee as one is the flawless performer of job duties and functions. For their assessment can be used purposefully developed scorecard to measure their compliance to the well-designed perfect employee.

Hence, the meaningful interpretation of the fuzzy model includes the selection and specification of three input and one output variable of the fuzzy output system. Table 1 presents the input and output variables of the regional banking sector staff assessment system.

Table 1. Input and output variables of the staff assessment system for banking

\begin{tabular}{|c|c|c|c|}
\hline $\begin{array}{l}\text { Variable } \\
\text { Symbol } \\
\end{array}$ & $\begin{array}{c}\text { Variable } \\
\text { Name } \\
\end{array}$ & Term-set & $\begin{array}{c}\text { Input } \\
\text { Options } \\
\end{array}$ \\
\hline$x_{1}$ & $\begin{array}{c}\text { Behavior } \\
\text { Towards } \\
\text { Colleagues } \\
\text { and } \\
\text { Costumers; }\end{array}$ & \multirow[t]{2}{*}{$\begin{array}{l}\text { low, medium, } \\
\text { high }\end{array}$} & \multirow[t]{2}{*}{$0-10$ points } \\
\hline$x_{2}$ & $\begin{array}{c}\text { Customer } \\
\text { Service } \\
\text { Quality }\end{array}$ & & \\
\hline$x_{3}$ & $\begin{array}{l}\text { Company } \\
\text { Loyalty }\end{array}$ & $\begin{array}{c}\text { positive, } \\
\text { neutral, } \\
\text { negative }\end{array}$ & $0-10$ points \\
\hline $\bar{y}$ & $\begin{array}{c}\text { Business } \\
\text { Efficiency }\end{array}$ & $\begin{array}{c}\text { low, medium, } \\
\text { high }\end{array}$ & $0-1$ point \\
\hline
\end{tabular}


The variables and the indicator, the input options were identified by surveys and observation.

Fuzzy Expert System was implemented in MATLAB with the Fuzzy Logic Toolbox extension package containing the following tools:

- Fuzzy Inference System Editor (FIS Editor);

- Membership Function Editor;

- Rule Editor;

- Rule View.

\section{Results}

The membership functions for the corresponding variables, allowing for variables, measured in points in the range of numbers from 0 to 10 , are normalized to a single segment. Their type was determined based on surveys of experts. Figures 1-3 present the membership functions of corresponding variables $-\mathrm{x}_{1}, \mathrm{x}_{2}, \mathrm{x}_{3}$. Figure 4 shows the membership function of the output variable $y$ (Manager Business Efficiency).

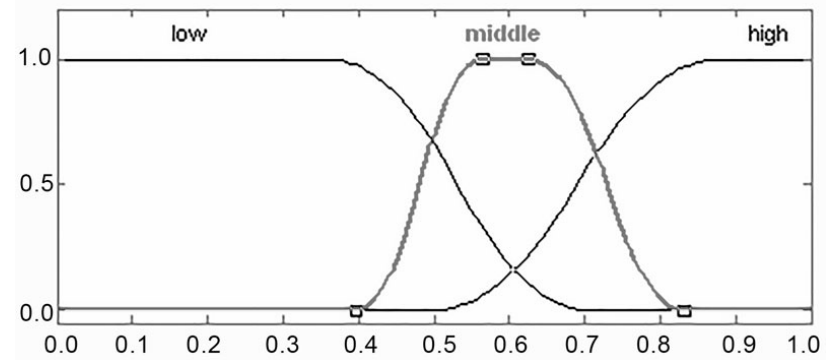

Fig. 1. The function of membership of variable $\mathrm{x}_{1}=$ Behaviour towards Colleagues and Costumers (Three linguistic terms: low, middle, high).

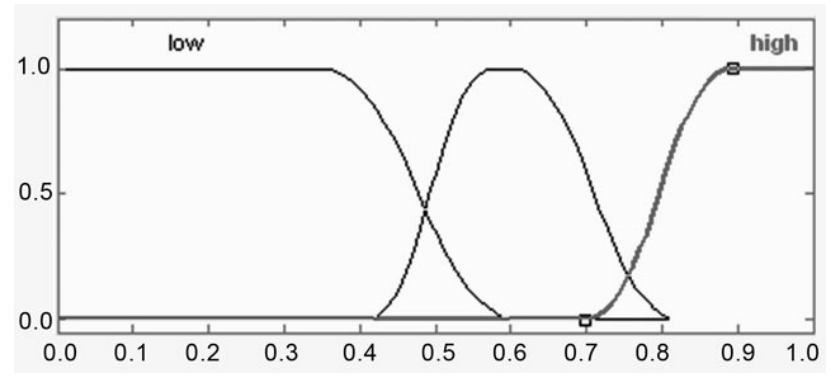

Fig. 2. The membership function for $\mathrm{x}_{2}=$ Customer Service Quality (Three linguistic terms: low, middle, high).

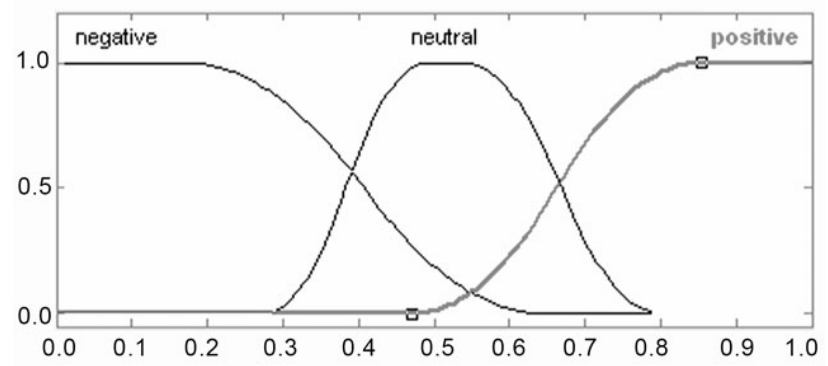

Fig. 3. Membership function for variable $\mathrm{x}_{3}=$ Company Loyalty (Three linguistic terms: negative, neutral, positive).

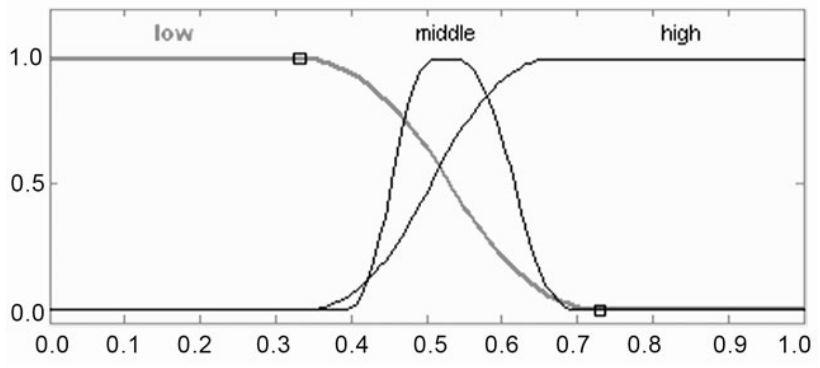

Fig. 4. The membership function of the output variable $\mathrm{y}=$ Business Efficiency of the Manager. (Three linguistic terms: low, middle, high).

Based on expert opinions and personal observations, the rules for the fuzzy expert system are set forth like following:

1) IF $x_{1}=$ Low AND $x_{2}=$ Middle AND $x_{3}=$ High then $\mathrm{y}=$ Middle;

2) IF $x_{1}=$ Middle AND $x_{2}=$ High AND $x_{3}=$ High, $y=$ High, etc.

Fig. 5 presents a visualization of the developed fuzzy expert system, indicating the connection between the input variables Company Loyalty, Quality of Service, Behaviour towards Colleagues and Costumers and the output variable Business Efficiency of the Manager.

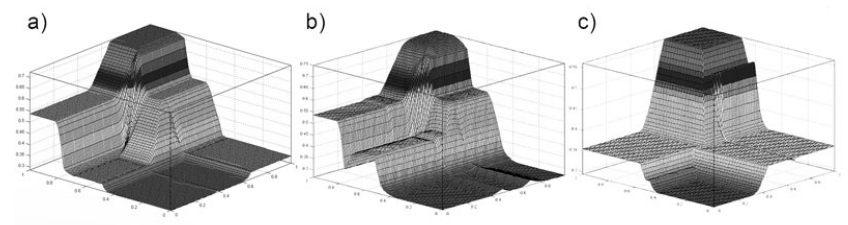

Fig. 5. The Fuzzy Logic Expert System:

a) dependence of output variable $y=$ Business Efficiency of Manager on input variables $\mathrm{x}_{1}=$ Company Loyalty and $\mathrm{x}_{2}=$ Customer Service Quality;

b) dependence of output variable y on input variables $\mathrm{x}_{1}=$ Company Loyalty and $\mathrm{x}_{2}=$ Customer Service Quality;

c) Dependence of output variable y on input variables $\mathrm{x}_{1}=$ Customer Service Quality and $\mathrm{x}_{2}=$ Behaviour towards Colleagues and Costumers.

Table 2 presents qualitative parameters of the bank staff assessment system fetched from the survey and through the fuzzy expert system. The last column presented quantitative indicators of managers' work which is the number of loan contracts for a given period.

Table 2. Qualitative parameters of the staff assessment system

\begin{tabular}{|c|c|c|c|c|c|}
\hline Staff & $\mathrm{x}_{1}$ & $\mathrm{x}_{2}$ & $\mathrm{x}_{3}$ & $\mathrm{y}$ & $\begin{array}{c}\text { Number } \\
\text { of credit } \\
\text { agreements } \\
\text { (pieces) }\end{array}$ \\
\hline Manager 1 & 0.8 & 0.5 & 0.7 & 0.563 & 17 \\
\hline Manager 2 & 0.6 & 0.8 & 0.8 & 0.729 & 19 \\
\hline Manager 3 & 0.5 & 0.4 & 0.4 & 0.29 & 11 \\
\hline Manager 4 & 0.7 & 0.9 & 0.8 & 0.738 & 20 \\
\hline Manager 5 & 0.4 & 0.3 & 0.6 & 0.271 & 10 \\
\hline \multicolumn{7}{|c}{} & $\ldots .7$ \\
\hline Manager 100 & 0.7 & 0.8 & 0.3 & 0.56 & 14 \\
\hline
\end{tabular}


Considering the variable Business Efficiency of the Manager as an explanatory variable, denoted as $\mathrm{X}$, and $\mathrm{N}$ as Number of Concluded Loan Contract as an explained variable, and based on the scatter plot, it is possible to put forward a hypothesis that the relationship between all possible values of $\mathrm{X}$ and $\mathrm{Y}$ of the population is linear:

$$
N=B 1 \cdot X+B 0+e r r .
$$

The regression equation, based on the data presented in Table 2, is the following:

$$
N=18.4815 \cdot X+5.782
$$

The sample linear correlation coefficient is 0.888 , which defines strong bidirectional causation between the $\mathrm{Y}$ and the $\mathrm{X}$ factor. The Student's criterion confirms the statistical significance of the regression coefficient.

The Fisher criterion for this model is met. Since the actual value is $\mathrm{F}>\mathrm{Ftab}$, the determining factor is statistically significant and the estimate of the regression equation is statistically reliable.

As a result, the following may be noted: the dependence of $\mathrm{Y}$ on $\mathrm{X}$ is studied. At this stage, a pair linear regression was selected. Its parameters are estimated by the least square method. The statistical significance of the equation is verified by the Fisher criterion. It is established that $78.91 \%$ of the total variability $\mathrm{Y}$ is explained by the change of $\mathrm{X}$.

It is also established that model parameters are statistically significant. An economic interpretation of model parameters is possible. An increase in $\mathrm{X}$ by 1 unit leads to an increase in $\mathrm{Y}$ on average by 18.481 units. The obtained estimates of the regression equation can be used to predict the effectiveness of the credit manager based on his qualitative estimates with no quantitative parameters.

\section{Conclusions}

In the research carried out, we showed that qualitative indicators are indispensable to assess the work of specialists and employees in the banking sector.

It is proposed to avail the fuzzy logic opportunities to interpret qualitative indicators of labour efficiency of the banking sector's employees.

The paper presents a fuzzy expert system that enables the credit personnel of banking institutions to be assessed on the basis of qualitative data and the results of the evaluation of the effectiveness of credit managers.

The developed fuzzy expert system can be used to assess the banking personnel, and in particular, the effectiveness of credit managers, especially in the recruitment of personnel; implementation of new projects is going on without any available quantitative indicators. This makes the approach effective for managerial decision making for staff hiring and promotion to be made in the banking and financial sector to minimize risks and increase efficiency.

\section{References}

1. N. Shportiuk, M. Sabadin, Int. Sci. J. Internauka. 15 (37) (2017).

2. Y. Odegov, M. Kulapov, O. Rakauskiene, P. Karasev, N. Fomenko, Mon. J. Econ. 17 (1) (2021).

3. I. Hatzilygeroudis, J. Prentzas, J. (2014). Sci. J. St. Comp. Int. 514 (2014).

4. A. Hernández, D. Hidalgo, Op. J. Bus. Mng. E 8, 6 (2020).

5. A. Ibragimov, L. Ibragimova, M. Karavayeva, Vestnik S. St. A. Un. E 1 (32) (2012)

6. V. Koretskiy, L. Józsa, I. Mardanova, M., Galiakhmetova, JEECAR, 6 (1), (2019).

7. S. Kalvakolanu, C. Madhavaiah. J. Adv. R. Dyn. Control. Sys. 11 (6) (2019).

8. J. Holt, S. Perry, A Pragmatic Guide to Competency: Tools, Frameworks and Assessment (BCS Learning \& Development Limited, 2011)

9. M. Jevscek, RUO. 5 (2) (2016).

10. D. Kryscynski, C. Reeves, R. Stice-Lusvardi, M., Ulrich, G. Russell, HRM, 57 (3), (2018).

11. N. Macwan, S. Srinivas. IJ End. I. Technol. 3 (2013)

12. N. Hasan, H. Elghareeb, F. Farahat, A. Abo Elfotouh, Int. J. F. L. and Int. Sys. 21 (1) (2021). 